\title{
Hypoxemia after an axial flow pump Jarvik-2000 implantation: Catheter induced
}

Joonhwa Hong, MD, Soon J. Park, MD, Sunil V. Mankad, MD, Frank Cetta, Jr, MD, Norman E. Torres, MD, and Morgan L. Brown, MD, Rochester, Minnesota

Left ventricular assist devices (LVADs) are now being implanted frequently as a bridge therapy to transplant or a destination therapy. ${ }^{1-3}$ Device technology is also changing in that nonpulsatile axial flow pumps are being used as frequently as pulsatile pumps at many centers. LVADs are effective in restoring circulation and unloading the left heart. LVAD support could result in a potential problem of right to left shunt through the patent foramen ovale (PFO), ${ }^{4-8}$ and the practice of performing transesophageal echocardiography (TEE) looking for PFO at the time of surgery has been well established. We describe an unusual case of significant hypoxemia resulting from a defect in the interatrial septum (IAS) created iatrogenically at the time of an electrophysiologic procedure in a patient who subsequently underwent an axial flow pump implantation.

\section{CLINICAL SUMMARY}

The patient was a 41-year-old man with advanced hypertrophic cardiomyopathy. He had a history of atrial fibrillation and had undergone a transcatheter-based atrioventricular nodal ablation procedure in the past. His condition continued to deteriorate, and he had to be listed for heart transplantation as status $1 \mathrm{~A}$ supported on 2 inotrope. His echocardiogram demonstrated severe concentric left ventricular hypertrophy with a small ventricular cavity. An estimated left ejection fraction was $35 \%$, and he had a small noncompliant ventricle. He was recommended to undergo LVAD implantation as a bridge therapy to heart transplantation. Given the patient's small left ventricular cavity, the Jarvik-2000 axial pump (Jarvik Heart Inc, New York, NY) was thought to be the best option for him.

Intraoperative TEE demonstrated a small hole in the IAS with a left to right shunt (Figure 1, $A$ ). We inspected the atrial septum to close this hole at the time of LVAD implantation. No PFO was noted. There were multiple small holes that were visible in the IAS, and the largest one that appeared to be communicating to left atrium was closed primarily. However, a persistent shunting between the 2 atria was noted on TEE after the patient was weaned from cardiopulmonary bypass support. The shunt was now in the direction of right to left (Fig-

From the Mayo Clinic, Rochester, Minnesota.

Received for publication Oct 8, 2007; accepted for publication Dec 2, 2007.

Address for reprints: Soon J. Park, MD, Cardiovascular Surgery, Mayo Clinic, 200

First Street SW, Rochester, MN 55905 (E-mail: park.soon@mayo.edu).

J Thorac Cardiovasc Surg 2008; 136:1082-3

$0022-5223 / \$ 34.00$

Copyright (c) 2008 by The American Association for Thoracic Surgery doi:10.1016/j.jtcvs.2007.12.066 ure $1, B$ ) with effective decompression of the left heart on Jarvik axial flow pump support. Because we had failed to identify the hole at the time of initial exploration of the IAS, we decided to close the hole percutaneously via the transcatheter route. The pump speed was reduced to 8000 from $11,000 \mathrm{rpm}$ to maintain as high arterial saturation as possible on $100 \%$ oxygen.

The patient was taken to the catheterization laboratory. Intracardiac echocardiography demonstrated a 3-mm hole in the lower part of the IAS with a significant right to left shunt (Figure 2, A). This defect was consistent with a puncture hole usually created in the lower IAS with a catheter from the inferior vena cava at the time of atrioventricular nodal ablation. The Amplatzer (AGA Medical Corp, Golden Valley, Minn) atrial septal defect closure device $(6 \mathrm{~mm})$ was inserted to close the shunt. A small residual right to left shunt remained through the device itself (Figure 2, $B$ ). Arterial saturation improved from $77 \%$ to a modest $90 \%$. Nonetheless, we brought the patient to the intensive care unit expecting further improvement in the arterial saturation over time. The small residual shunt within the Amplatzer device was expected to close soon by forming clots over the mesh. The patient also had significant intrapulmonary shunt based on sampled pulmonary venous blood $\mathrm{Po}_{2}$ of $114 \mathrm{~mm} \mathrm{Hg}$ on $100 \%$ oxygen before atrial septal defect closure. Arterial saturation increased up to $96 \%$ within 1 hour. The patient's condition continued to improve. $\mathrm{His} \mathrm{FiO}_{2}$ requirement decreased to 0.4 by the third day, and he was extubated on the sixth day after LVAD insertion. A follow-up echocardiography revealed no residual shunt through the IAS, and the patient remains on the waiting list for heart transplantation.

\section{DISCUSSION}

There are several case reports of hypoxemia resulting from right to left shunt through the IAS after LVAD implantation. ${ }^{4-8}$ Reported cases of shunting usually involve PFO after implantation of pulsatile LVADs. At most centers, performing a TEE study looking for intracardiac shunt through a PFO has been a matter of routine practice., ${ }^{4,5}$ Our patient developed significant hypoxemia from the right to left shunt through a 3-mm hole created iatrogenically at the time of the electrophysiology procedure. An axial flow pump may create a more significant right to left shunt than a pulsatile pump because it unloads the heart continuously and more effectively depending on the setting of the motor speed. Even a small hole can result in clinically significant hypoxemia with an axial flow pump. 


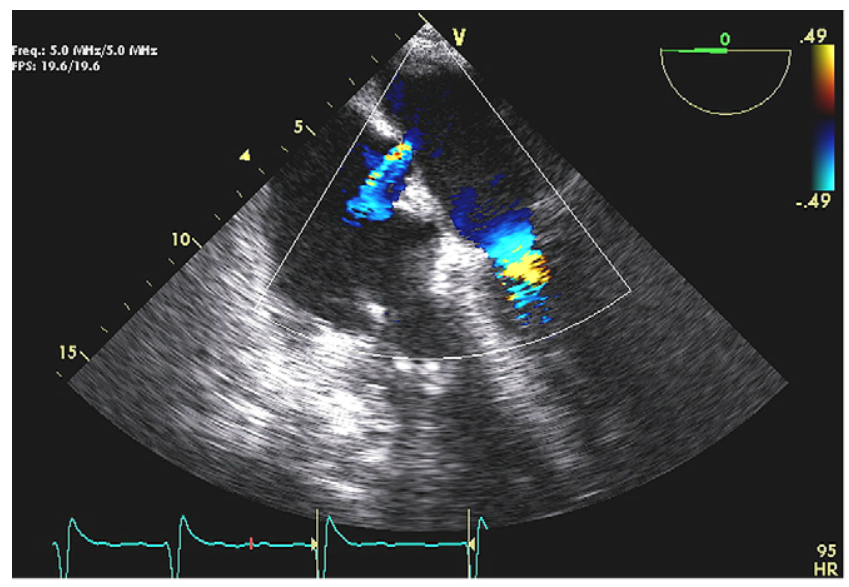

A

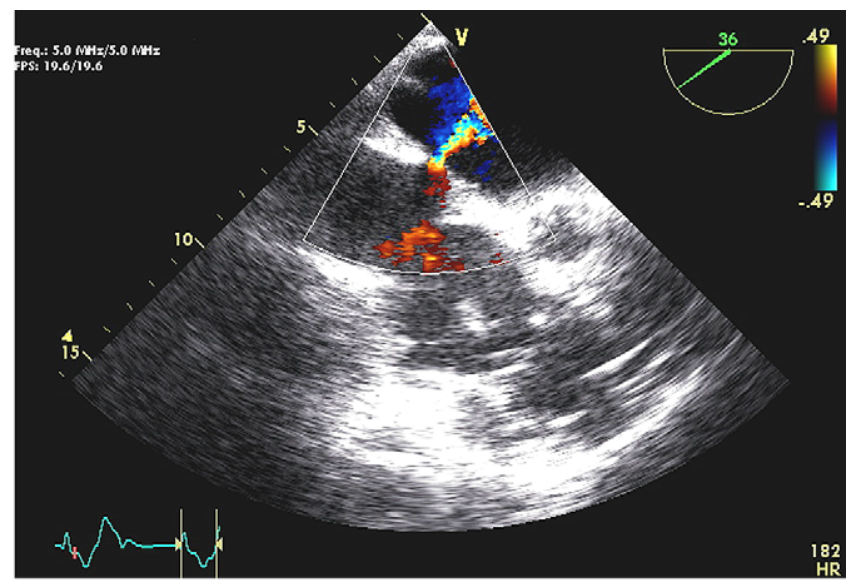

B

FIGURE 1. A, Intraoperative TEE showing a left to right shunt through the atrial septum before the LVAD implantation. B, Intraoperative TEE showing a right to left shunt through the atrial septum after LVAD implantation.

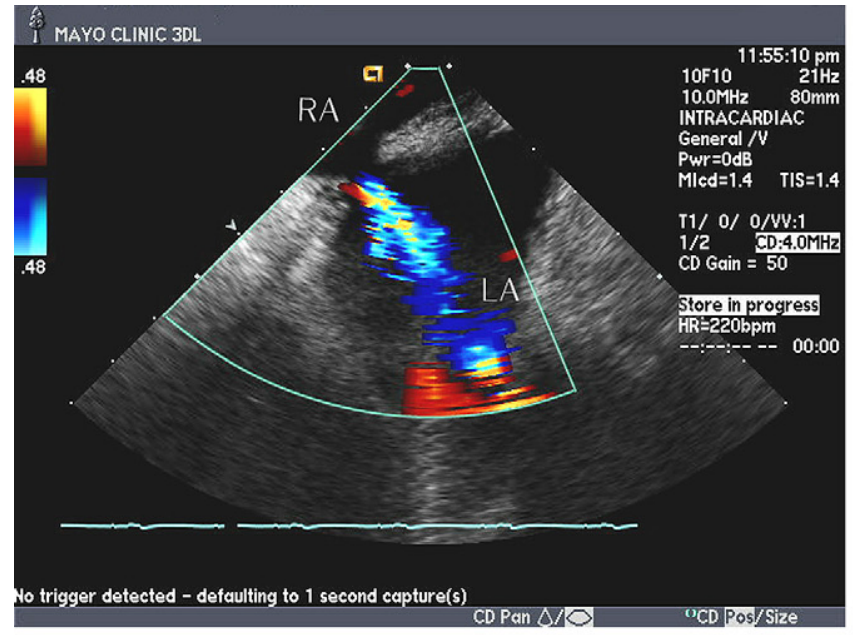

A

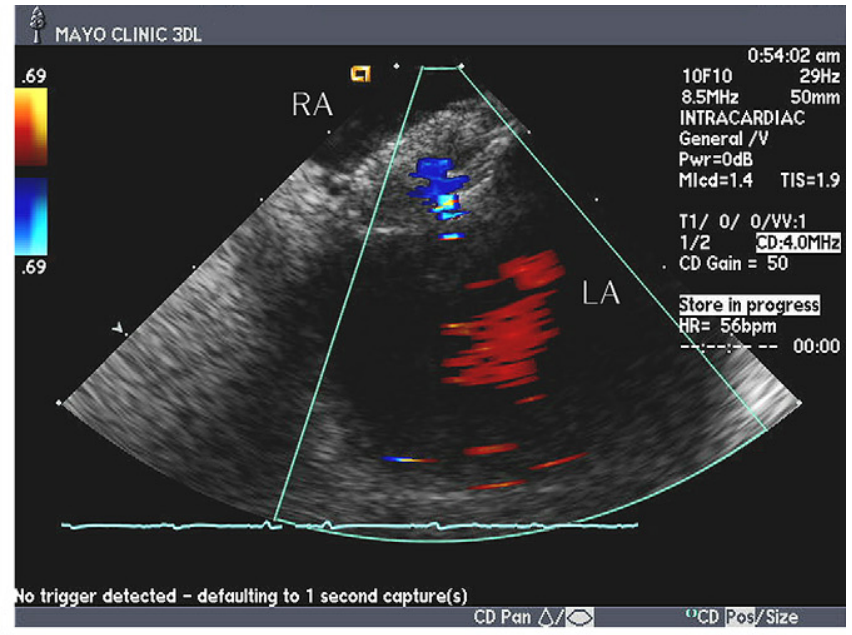

B

FIGURE 2. A, Intracardiac echocardiogram showing a right to left shunt through the atrial septum. B, Intracardiac echocardiogram showing a tiny residual shunt after atrial septal defect closure using the Amplatzer device (AGA Medical Corp, Golden Valley, Minn). RA, Right atrium; LA, left atrium.

\section{CONCLUSIONS}

All intracardiac shunts should be closed at the time of surgery for LVAD implantation. However, if hypoxemia from an untreated intracardiac shunt develops in a patient, measures such as reducing airway pressure, inotropic support of right heart function, and agents to reduce pulmonary vascular resistance can be helpful as a temporizing measure. ${ }^{5,8}$ LVAD flow should be reduced to elevate left atrial pressure while maintaining adequate tissue perfusion. Most importantly, the shunt needs to be closed promptly. A transcatheter-based percutaneous closure of an intracardiac shunt can be an effective option.

\section{References}

1. Rose EA, Gelijns AC, Moskowitz AJ, et al, for the Randomized Evaluation of Mechanical Assistance for the Treatment of Congestive Heart Failure (REMATCH)
Study Group. Long-term mechanical left ventricular assistance for end-stage heart failure. N Engl J Med. 2001;345:1435-43

2. Park S, Tector A, Piccioni W, et al. Left ventricular assist devices as destination therapy: a new look at survival. J Thorac Cardiovasc Surg. 2005;129:9-17.

3. Lietz K, Long JW, Kfoury AG, et al. Outcomes of left ventricular assist device implantation as destination therapy in the post-REMATCH era: implications for patient selection. Circulation. 2007;116:497-505.

4. Baker JE, Stratmann G, Hoopes C, et al. Profound hypoxemia resulting from shunting across an inadvertent atrial septal tear after left ventricular assist device placement. Anesth Analg. 2004;98:937-40.

5. Kilger E, Strom C, Frey L, et al. Intermittent atrial level right to left shunt with temporary hypoxemia in a patient during support with a left ventricular assist device. Acta Anaesthesiol Scand. 2000;44:125-7.

6. Baldwin RT, Duncan JM, Frazier OH, et al. Patent foramen ovale: a cause of hypoxemia in patients on left ventricular support. Ann Thorac Surg. 1991;52:865-7.

7. Nguyen DQ, Das GS, Grubbs BC, et al. Transcatheter closure of patent foramen ovale for hypoxemia during left ventricular assist device support. J Heart Lung Transplant. 1999;18:1021-3.

8. Srinivas CV, Collins N, Borger MA, Horlick E, Murphy PM. Hypoxemia complicating LVAD insertion: novel application of the Amplatzer PFO occlusion device. J Card Surg. 2007;22:156-8. 